\title{
The grass-living thrips (Insecta: Thysanoptera) from Iran with the first record of the genus Arorathrips Bhatti
}

\author{
K. Minaei, M. Alichi \\ Department of Plant Protection, College of Agriculture, Shiraz University, Shiraz, Iran
}

\begin{abstract}
A list of grass-dependent Thysanoptera genera in Iran is provided, including Arorathrips with one species, A. mexicanus, a Chirothripsrelated thripid genus as a new record for Iranian fauna. The specimens of this species were collected from mixed grasses in the city of Minab located in Hormozgan Province, south of Iran. The importance of grasses as host plants for members of the family Thripidae is briefly discussed.
\end{abstract}

\section{Introduction}

The members of the insect order Thysanoptera exhibit a wide range of bionomics. About $50 \%$ are fungivorous, feeding on the hyphae or spores of fungi (Mound, 2003). Of the remaining species, although a few are obligate predators on other small arthropods (Palmer \& Mound, 1990), most of them are phytophagous, including several opportunist species considered as crop pests (Lewis, 1997; Moritz et al., 2004). Nine families are recognized in the order Thysanoptera (Mound et al., 2013), of which five (Aeolothripidae, Stenurothripidae,

Correspondence: Kambiz Minaei, Department of Plant Protection, College of Agriculture, Shiraz University, Shiraz, Iran.

E-mail:kminaei@shirazu.ac.ir

Key words: Arorathrips mexicanus, Hormozgan Province, new record, Poaceae.

Acknowledgements: the authors would like to thank Agricultural Research, Education and Extension Organization of Hormozgan for providing facilities during field work in Hormozgan. The manuscript was improved through the advice kindly provided by two anonymous reviewers.

Received for publication: 15 March 2013.

Revision received: 1 June 2013.

Accepted for publication: 7 June 2013.

(C) Copyright K. Minaei and M. Alichi, 2013

Licensee PAGEPress, Italy

Journal of Entomological and Acarological Research 2013; 45:e12

doi:10.4081/jear.2013.e12

This article is distributed under the terms of the Creative Commons Attribution Noncommercial License (by-nc 3.0) which permits any noncommercial use, distribution, and reproduction in any medium, provided the original author(s) and source are credited.
Melanthripidae Phlaeothripidae, Thripidae) have been recorded in Iran so far (Minaei \& Alichi, 2007).

The objective of this paper is to provide a list of Thysanoptera genera in which species breed on grasses (family Poaceae) in Iran, and to record the genus Arorathrips Bhatti as another grass-dwelling genus, for the first time in this country. Illustrations and diagnostic characters are also included. Full nomenclatural information about Thysanoptera is available on the web (ThripsWiki, 2013).

\section{Materials and methods}

The list of Iranian thrips that are associated with grasses is extracted from the published literature. The species discussed here, $A$. mexicanus (Crawford), was collected by beating mixed grasses (Poaceae) onto a plastic tray. The specimens were removed with a fine brush into a collecting vial containing $90 \%$ ethyl alcohol. They were then mounted onto slides in Canada balsam using the protocol of Mound \& Kibby (1998). Microphotographs were obtained using a Dino-Lite Microscope, Eyepiece Camera. Digital images were enhanced and plates prepared by Adobe Photoshop ${ }^{\mathrm{TM}}$ (Adobe Systems Inc., San Jose, CA, USA). The terminology used here follows Minaei \& Mound (2010a) and Hoddle et al. (2013). All specimens studied are deposited in the collection of the Plant Protection Department, College of Agriculture, Shiraz University, Shiraz, Iran.

\section{Results}

The only recorded member of the family Stenurothripidae in Iran, Holartrothrips josephi Bhatti, feeds on the pollen of date palm (Bhatti, 1986). Concomitantly, two genera of Melanthripidae (Ankothrips Bagnall and Melanthrips Bagnall) include flower-feeding species in various plant families (Minaei et al., 2012). Grass-living thrips are distributed among another three families. Among these, there are a few species that breed on grasses in Aeolothripidae and Phlaeothripidae, but most grass-living Thysanoptera belong to the family Thripidae, including Arorathrips mexicanus, which is discussed below.

\section{Arorathrips mexicanus (Crawford)}

Chirothrips mexicana D.L. Crawford 1909: 114.

Arorathrips mexicanus (Crawford); Bhatti 1990: 196.

The genus Arorathrips was separated by Bhatti (1990) from the genus Chirothrips, and four species were placed in the new genus at that time. However, currently 15 species are placed in this genus, all of which are considered endemic to the New World and breed only in the flowers of grasses (Mound \& Marullo, 1996; Mound, 2011; Nakahara \& Foottit, 2012). Arorathrips mexicanus is recorded here from Iran, and 
this is the first record of this genus and species in this country. The genus is distinguished from the closely related genus, Chirothrips, in having the mesothoracic endofurca greatly reduced and fore tibia prolonged around the external margin of the fore tarsus.

DIAGNOSIS: Female fully winged. Body color light brown, tarsi yellow, forewing and clavus shaded (Figure 1). Antennae 8-segmented, segment I with median dorsal setal pair wider apart than width of base of segment II, segment II distinctly produced at apex on outer margin with terminal sensorium, segments III-IV with simple sensorium (Figure 2). Head small, with a distinct prolongation in front of eyes, vertex with three pairs of setae. Pronotum trapezoidal, two pairs of prominent posteroangular setae present (Figure 3). Mesothoracic endofurca reduced (Figure 4). Fore tibia extending around external margin of fore tarsus (Figure 5). Tergites with transverse sculpture lines medially; antecostal ridge of tergites II-V with row of small tubercles; campaniform sensilla anterior to median, its setae on tergites I-VIII. Sternites II-IV medially with pattern of tubercles.

Male smaller, wingless, yellow (Figure 6); sternites III-VII medially with circular glandular area (Figure 7).

MATERIAL EXAMINED: 5 females, 5 males, Hormozgan, Minab, from mixed grasses, 20.1.2009 (KM 259).

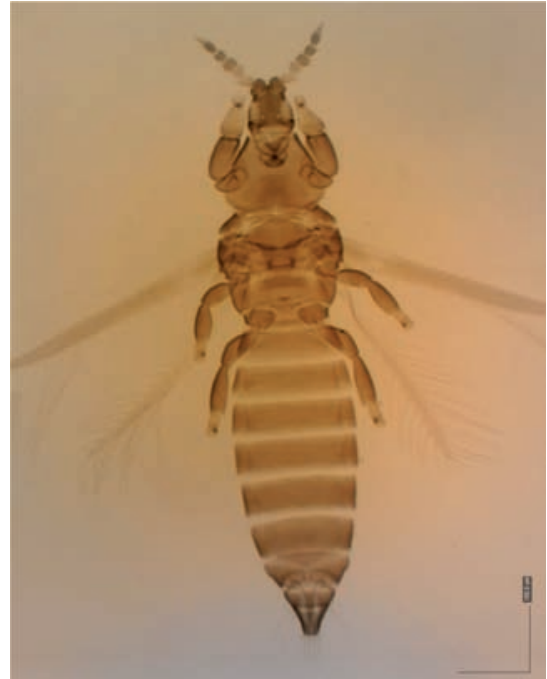

Figure 1. Arorathrips mexicanus, female: adult.

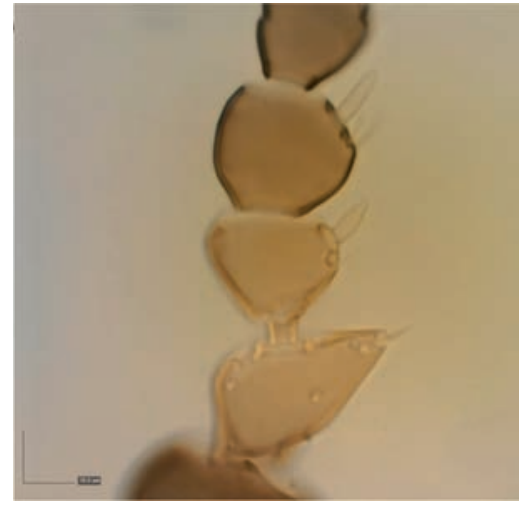

Figure 2. Arorathrips mexicanus, female: antennal segments II-IV.

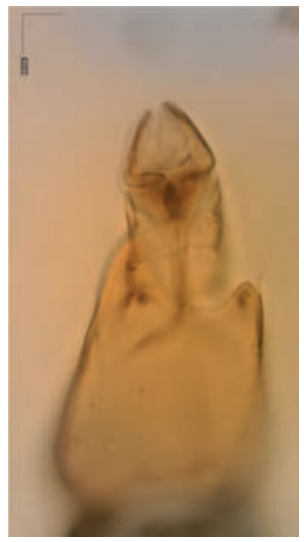

Figure 5. Arorathrips mexicanus, female: foretibia and tarsus.

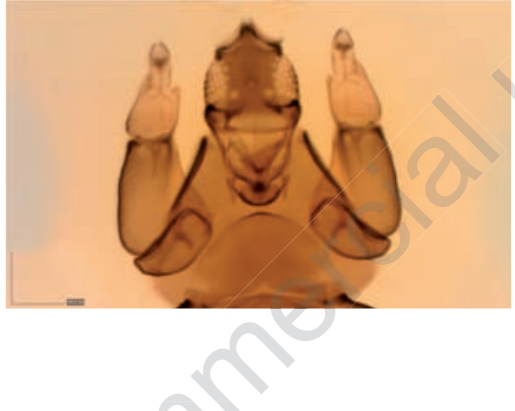

Figure 3. Arorathrips mexicanus, female: head and pronotum.
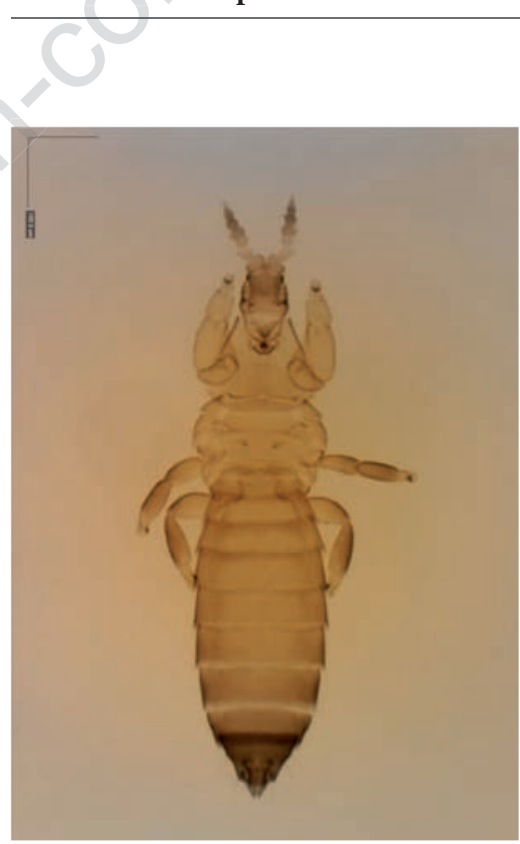

Figure 6. Arorathrips mexicanus, male: adult.

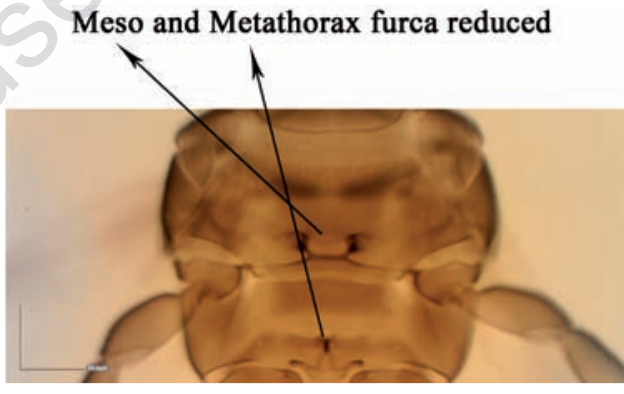

Figure 4. Arorathrips mexicanus, female: meso and metathorax furca reduced.

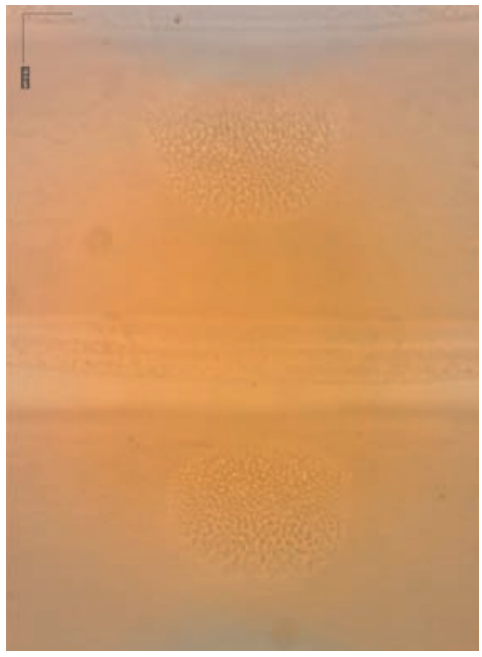

Figure 7. Arorathrips mexicanus, male: sternites vi-vii. 
Table 1. The genera of Thysanoptera associated with grasses in Iran.

\begin{tabular}{|c|c|c|}
\hline Family & Genus & Reference \\
\hline Aeolothripidae & $\begin{array}{l}\text { Aeolothrips Haliday* } \\
\text { Rhipidothrips Uzel }\end{array}$ & $\begin{array}{l}\text { Hoddle et al., } 2013 \\
\text { Mound et al., } 1976\end{array}$ \\
\hline Phlaeothripidae & $\begin{array}{c}\text { Haplothrips Amyot and Serville* } \\
\text { Cephalothrips Uzel }\end{array}$ & $\begin{array}{l}\text { Minaei \& Mound, } 2008 \\
\text { Hoddle et al., } 2013\end{array}$ \\
\hline Thripidae & $\begin{array}{l}\text { Anaphothrips } \text { Uzel }^{*} \\
\text { Aptinothrips } \text { Haliday } \\
\text { Arorathrips } \text { Bhatti } \\
\text { Bregmatothrips Hood } \\
\text { Caliothrips Daniel } \\
\text { Chirothrips Haliday } \\
\text { Collembolothrips } \text { Priesner } \\
\text { Eremiothrips } \text { Priesner } \\
\text { Exothrips Priesner } \\
\text { Florithrips } \text { Bhatti } \\
\text { Frankliniella Karny } \\
\text { Limothrips Haliday } \\
\text { Sitothrips } \text { Priesner } \\
\text { Sphaeropothrips Priesner } \\
\text { Stenchaetothrips Bagnall } \\
\text { Stenothrip Uzel }\end{array}$ & $\begin{array}{c}\text { Mound \& Masumoto, } 2009 \\
\text { Palmer, 1975 } \\
\text { Nakahara \& Foottit, } 2012 \\
\text { zur Strassen, 2003 } \\
\text { Wilson, 1975 } \\
\text { Minaei \& Mound, 2010a } \\
\text { zur Strassen, 2003 } \\
\text { Ramezani et al., } 2009 \\
\text { Bhatti, 1975 } \\
\text { Ramezani et al., } 2012 \\
\text { Mound } \text { et al., } 1976 \\
\text { zur Strassen, 2003 } \\
\text { zur Strassen, } 2003 \\
\text { Minaei } \text { et al., } 2007 \\
\text { zur Strassen, } 2003 \\
\text { zur Strassen, } 2003\end{array}$ \\
\hline
\end{tabular}

${ }^{*}$ Not all species breeding on grasses.

\section{Discussion and conclusions}

About 40 Thripidae genera are recorded from Iran (Bhatti et al., 2009), and a large proportion of these (about 40\%) live on grasses (Table 1). This is in accordance with the situation reported from Australia (Mound, 2011). Grasses support a rich fauna of thrips (Table 1), possibly due to the availability of a range of such plants in most areas (unpublished lecture by LA Mound at $20^{\text {th }}$ Iranian Plant Protection Congress, Shiraz, Iran, August 2012). Some of the species in the genera listed in Table 1 are considered plant pests in other countries (Lewis, 1997; Moritz et al., 2004). However, no thripid pest is recorded on grasses in Iran. In contrast, one of the species in the family Phlaeothripidae, Haplothrips tritici (Kurdjumov) (Minaei \& Mound, 2008, 2010b), is an important pest throughout Iran on wheat.

All species in the genus Arorathrips have been considered endemic to the New World (Mound \& Marullo, 1996; Mound, 2011; Nakahara \& Foottiit, 2012). However, the presence of $A$. mexicanus is not surprising in Iran because this species is introduced around the world and is widely distributed in the tropics and subtropics in association with grasslands (Mound \& Palmer, 1972; Mound \& Marullo, 1996).

\section{References}

BHATTI J.S., 1975 - A revision of Exothrips Priesner and two related genera. - Orient. Insects. 9: 43-90.

BHATTI J.S., 1986 - A new species of Holarthrothrips from Iraq, with notes on host plants and key to species, along with clarification of the position of this genus among Thysanoptera. - Zoology (JPAZ). 1: 1-33.

BHATTI J.S., 1990 - On some genera related to Chirothrips (Insecta: Terebrantia: Thripidae). - Zoology (JPAZ). 2: 194-200.

BHATTI J.S., ALAVI J., ZUR STRASSEN R., TELMADARRAIY Z., 2009 -
Thysanoptera in Iran 1938-2007. An overview. Part 1. - Thrips. 7: 1-82. CRAWFORD D.L., 1909 - Some Thysanoptera of Mexico and the south. I. - Pomona Coll. J. Entomol. l: 109-119.

HODDLE M.S., MOUND L.A., PARIS D., 2013 - Thrips of California 2012. Available from: http://keys.lucidcentral.org/keys/v3/thrips_of_california/Thrips_of_California.html Accessed: 15 March 2013.

LEWIS T., 1997 - Pest thrips in prespective. In: LEWIS T. (ed.), Thrips as crop pests. - CAB International, Wallingford: 1-13.

MINAEI K., ALICHI M., 2007 - Thysanoptera fauna of Shiraz and vicinity. - J. Insect Sci. 7: 22-23.

MINAEI K., AZMAYESHFARD P., MOUND L.A., 2007 - The Thrips genusgroup (Thysanoptera: Thripidae) in Iran. - J. Entomol. Soc. Iran 27: 29-36.

MINAEI K., HAFTBARADARAN F., MOUND L.A., 2012- A new Ankothrips species (Thysanoptera: Melanthripidae) from Iran with unusually short setae. - Zootaxa. 3552: 37-42.

MINAEI K., MOUND L.A., 2008 - The Thysanoptera Haplothripini (Phlaeothripidae) of Iran. - J. Nat. His. 42: 2617-2658.

MINAEI K., MOUND L.A., 2010a - Grass-flower thrips of the genus Chirothrips (Thysanoptera: Thripidae), with a key to species from Iran. - Zootaxa. 2411: 33-43.

MINAEI K., MOUND L.A., 2010b - Taxonomic problems in character state interpretation: variation in the wheat thrips Haplothrips tritici (Kurdjumov) (Thysanoptera: Phlaeothripidae) in Iran. - Dtsch. Entomol. Z. 57: 233-241.

MORITZ G., MOUND L.A., MORRIS D.C., GOLDARAZENA A., 2004 - Pest thrips of the world: an identification and information system using molecular and microscopical methods. CD-ROM. Cent. Biol. Inf. Technol, Brisbane.

MOUND L.A., 2003 - Thysanoptera. In: RESH V.H., CARDE R.T. (eds.), The encyclopedia of insects. - Academic Press, St. Louis: 1127-1132.

MOUND L.A., 2011 - Grass-dependent Thysanoptera of the family Thripidae from Australia. - Zootaxa 3064: 1-40.

MOUND L.A., DESLEY T., PARIS, D., 2013 - OZ THRIPS, Thysanoptera in Australia. Available from: http://www.ozthrips.org/terebrantia/ aeolothripidae/ Accessed: 15 March 2013. 
MOUND L.A., KIBBY G., 1998 - Thysanoptera: an identification guide. Second edition. - CAB International Institute of Entomology and British Museum (Natural History), London: 70 pp.

MOUND L.A., MARULLO R., 1996 - The Thrips of Central and South America: an introduction (Insecta: Thysanoptera). - Mem. Entomol. Int. 6: 1-488.

MOUND L.A., MASUMOTO M., 2009 - Australian Thripinae of the Anaphothrips genus-group (Thysanoptera), with three new genera and thirty-three new species. - Zootaxa. 2042: 1-76.

MOUND L.A., MORISON G.D., PITKIN B.R., PALMER J.M., 1976 Thysanoptera. Handbooks for the identification of British insects, vol. 1. Royal Entomological Society of London (RES), London: 1-79.

MOUND L.A., PALMER J.M., 1972 - Grass-flower infesting thrips of the genus Chirothrips Haliday in Australia. - J. Aust. Entomol. Soc. 11: 332-339.

NAKAHARA S., FO0TTIT R.G., 2012 - Review of Chirothrips and related genera (Thysanoptera: Thripidae) of the Americas, with descriptions of one new genus and four new species. - Zootaxa. 3251: 1-29.
PALMER J.M., 1975 - The grass-living genus Aptinothrips (Thysanoptera: Thripidae). - J. Entomol. 44: 175-188.

PALMER J.M., MOUND L.A., 1990 - Thysanoptera In: ROSEN D. (ed.), The armoured scale insects, their biology, natural enemies and control. - Elsevier, Amsterdam: 67-75.

RAMEZANI L., BHATTI J.S., MOSSADEGH M.S., SOLEIMANNEJADIAN E., 2009 - Discovery of Eremiothrips similis Bhatti 1988 in Iran (Insecta: Terebrantia: Thripidae). - Thrips. 11: 1-18.

RAMEZANI L., MOSSADEGH M.S., SOLEIMANNEJADIAN E., BAGHERI S., MINAEI K., 2012 - The first report of the genus and species of Florithrips traegardhi (Thysa.: Thripidae) from Iran. - J. Entomol. Soc. Iran 31: 101-103. [In Persian].

THRIPSWIKI, 2013 - ThripsWiki - providing information on the World's thrips. Available from: thrips.info/wiki/ Accessed: 1 June 2013.

WILSON T.H., 1975 - A monograph of the subfamily Panchaetothripinae (Thysanoptera: Thripidae). - Mem. Am. Entomol. Inst. 23: 1-354.

ZUR STRASSEN R., 2003 - Die Terebranten Thysanopteren Europas und des Mittelmeer-Gebietes. - Die Tierwelt Deutschlands 74: 1271. [In German]. 